\title{
Letter to Editor
}

Journal of Applied Pharmaceutical Science Vol. 5 (10), pp. 157-159, October, 2015

Available online at http://www.japsonline.com

DOI: $10.7324 / \mathrm{JAPS} .2015 .501028$

ISSN 2231-3354 (cc) BY-NC-SA

\section{Activated charcoal for oral medicinal purposes: Is it really activated?}

Dear Editor,

ctivated charcoal is commonly used as oral
medication to lower cholesterol level, (Neuvonen et al.,1989), treat poisonings (Olson, 2010) and reduce intestinal gas (Hall et al.,1981). In general, activated charcol is not toxic and safe to be used in oral administration as it is not digested in human gastrointestinal tract (Olson, 2010). Activated charcoal can be manufactured from a variety of carbonaceous materials such as woods, coal and agricultural by-products. There are two ways to activate the carbonaceous precursors into activated charcoal, namely physical activation and chemical activation. For medicinal applications, physical activation is preferable because it involves the use of inert, non-toxic oxidizing gases (such as steam or $\mathrm{CO}_{2}$ ) instead of toxic chemical agents (such as $\mathrm{ZnCl}_{2}$ and $\mathrm{KOH}$ ) in chemical activation that may in some way compromise the safety of the product. In physical activation, the precursor is carbonized at $300-500^{\circ} \mathrm{C}$ in air or $\mathrm{N}_{2}$ atmosphere prior to pyrolysis at high temperature $\left(800-1000^{\circ} \mathrm{C}\right)$. The former is to create rudimentary pores on the material surface, while the latter enhances the textural properties by increasing the pore volume and specific surface area of the resultant activated charcoal (Marsh and Rodriguez-Reinoso, 2006). Figure 1 visualizes the pore development in the physical activation process. The image was taken using Field Emission Scanning Electron Microscope (FESEM, model SUPRA 35VP) at 2500 magnification.

By definition, activated charcoal is a carbon material with unique surface and textural properties, where the carbon content is usually more than $80 \%$ and the specific surface area is between 700 and $2000 \mathrm{~m}^{2} / \mathrm{g}$ (Ming-Twang et al., 2015). Activation procedure releases the volatiles - hydrogen, sulphur, nitrogen and oxygen, resulting a graphitic structure carbon-rich material (Marsh and Rodriguez-Reinoso, 20064, Ming-Twang et al., 2015). The fact that activated charcoal is good at capturing toxins and cholesterol from being absorbed into the body through blood vessels is undeniable (Olson, 2010; Neuvonen et al.,1989; Hall et al.,1981). This is usually being perceived as the charcoal has been 'activated' that enables it to perform its duties.

\footnotetext{
Muhammad Abbas AHMAD ZAINI ${ }^{1}$, Nur Atika MOHAMAD ${ }^{2}$

${ }^{1}$ Centre of Lipids Engineering \& Applied Research, Ibnu Sina Institute for Scientific \& Industrial Research, Universiti Teknologi Malaysia, Johor Bahru, Malaysia. ${ }^{2}$ Taman Universiti Medical Centre, Ministry of Health Malaysia, Johor Bahru, Malaysia. Email:abbas@cheme.utm.my
}

However, to what extent the charcoal is 'activated' is still widely not understood among the pharmacologists and medical practitioners. To elucidate the properties of pharmaceutical grade activated charcoal, attempt has been made to compare its characteristics with that of commercial activated carbon.

Activated charcoal tablet (DynaPharm, $250 \mathrm{mg}$ ) was purchased from local pharmacy, while the commercial activated carbon (powder) was obtained from R\&M Chemicals. Activated charcoal tablet and commercial activated carbon, thereinafter are designated as ACT and CAC, respectively. A tablet of activated charcoal was ground to powder form to ease the characterization. Both materials were characterized according to specific surface area and textural properties (Surfer Sorptomatic, Thermo Electron Corp.), elemental composition (vario Micro cube, Elementar) and adsorptive behaviour (bottle-point technique). Table 1 shows the chemical composition of activated charcoals. Clearly, ACT possesses lower carbon content and higher fraction of volatiles than CAC. It indicates that the physical activation has not been carried out sufficiently in the production of ACT. This could be due to activation performed at lower temperature, or perhaps the activation is too rapid for the development of pores to take place. The lower carbon content of ACT also suggests that the graphitic (aromatic) structure is not completely developed, thus the material could not be said as being 'activated'.

Table 1: Chemical composition of activated charcoals.

\begin{tabular}{lcc}
\hline & \multicolumn{2}{c}{ Sample } \\
\cline { 2 - 3 } & CAC & ACT \\
\hline Moisture content (\%) & 6.73 & 6.66 \\
Ash content (\%) & 5.26 & 2.61 \\
Elemental composition (\%, d.a.f) & & \\
Carbon & 84.3 & 55.4 \\
Hydrogen & 0.795 & 4.37 \\
Nitrogen & 0.194 & 1.3 \\
Sulfur & 0.016 & 0.619 \\
Oxygen (by difference) & 14.7 & 38.3 \\
\hline
\end{tabular}

Table 2: Textural properties of activated charcoals.

\begin{tabular}{lcc} 
& \multicolumn{2}{c}{ Sample } \\
\cline { 2 - 3 } & CAC & ACT \\
\hline Specific surface area $\left(\mathrm{m}^{2} / \mathrm{g}\right)$ & 909 & 30.7 \\
Micropore surface $\operatorname{area}\left(\mathrm{m}^{2} / \mathrm{g}\right)$ & 748 & 12.6 \\
Mesopore surface $a r e a\left(\mathrm{~m}^{2} / \mathrm{g}\right)$ & 161 & 18.1 \\
Total pore volume $\left(\mathrm{cm}^{3} / \mathrm{g}\right)$ & 0.442 & 0.0641 \\
Micropore volume $\left(\mathrm{cm}^{3} / \mathrm{g}\right)$ & 0.347 & 0.0116 \\
Mesopore volume $\left(\mathrm{cm}^{3} / \mathrm{g}\right)$ & 0.095 & 0.0525 \\
Microporosity $(\%)$ & 78.5 & 18.1 \\
Average pore width $(\mathrm{nm})$ & 1.94 & 9.37 \\
\hline
\end{tabular}


Table 2 summarizes the textural properties of activated charcoals. The results are in agreement with the chemical composition of activated charcoals in Table 1 . In activation, the release of volatiles and the restructuring of carbon backbone to form the graphitic structure giving rise to the pore volume, hence increasing the specific surface area. From Table 2, the specific surface area of CAC is nearly thirty times greater than that of ACT. As far as the tableting process is concern, it is unlikely that the lower specific surface area is a result from the compressing of activated charcoal powder into tablet. The compression only decreases the external surface area, while effective (specific) surface area remains intact and slightly unchanged as it is developed by the internal porous texture. In Figure1, the carbonization at $300^{\circ} \mathrm{C}$ yields specific surface area of $<10 \mathrm{~m}^{2} / \mathrm{g}$, while it increases to nearly $1000 \mathrm{~m}^{2} / \mathrm{g}$ after activation. Table 2 also shows that CAC is highly microporous with average pore width of $1.9 \mathrm{~nm}$, while ACT is rich in mesopores with pore width centred at $9.4 \mathrm{~nm}$. Although pharmaceutical-based activated charcoal has already in the market for many years, the use of 'activated' term seems to be over exaggerating than it supposes to be. The activated charcoal tablet (ACT) that we examined exhibits a lower carbon content, and inferior total pore volume and specific surface area than the commercial activated carbon (CAC).

Another parameter of concern that was evaluated is the adsorptive characteristic of activated charcoals. For this purpose, methylene blue dye powder ( $\mathrm{HmbG}$ Chemicals, $\mathrm{C}_{16} \mathrm{H}_{18} \mathrm{ClN}_{3} \mathrm{~S}$, assay $98.5 \%$ ) was employed as adsorbate or model toxin (Zaini et al., 2013). About $50 \mathrm{mg}$ of activated charcoal was brought into intimate contact with $50 \mathrm{~mL}$ methylene blue solution of varying concentrations. The mixture was allowed to equilibrate at room temperature, and the residual concentration was measured using spectrophotometer (Halo vis-10, Dynamica) at a wavelength of $508 \mathrm{~nm}$. Figure 2 displays the uptake of methylene blue onto activated charcoals with increasing equilibrium concentration. In general, both materials display a steep gradient (parallel to y-axis) that indicates favourable and high intensity adsorption. This is associated with the removal percentage that begin to decrease from nearly $100 \%$ to $98.7 \%$ at initial concentration of 52 and $340 \mathrm{mg} / \mathrm{L}$ for ACT and CAC, respectively. The maximum methylene blue uptake were recorded as 65 and $344 \mathrm{mg} / \mathrm{g}$, for ACT and CAC, respectively. It is clear that the uptake of methylene blue is driven by the textural properties of CAC. For both activated charcoals, the maximum uptake of methylene blue is correlated well with the total pore volume, ca. $0.9 \mathrm{~g} / \mathrm{cm}^{3}$. It implies that the methylene blue molecules satisfactorily lodge on the porous textures of activated charcoals via $\pi-\pi$ interaction and/or weak intermolecular (van der Waals) forces (Olson, 2010). The trend of methylene blue uptake onto CAC could be adequately modelled by Langmuir isotherm as $q_{e}=835 \cdot C_{e} /\left(1+2.38 \cdot C_{e}\right)$, where $q_{e}(\mathrm{mg} / \mathrm{g})$ and $C_{e}(\mathrm{mg} / \mathrm{L})$ are methylene blue uptake and equilibrium concentration, respectively. It suggests that the adsorption of methylene blue is monolayer in nature and occurs on the homogeneous surface of CAC. On the other hand, the modified Langmuir expression, $q_{e}=$ $258 \cdot C_{e} \cdot e^{-C e / 926} /\left(1+3.80 \cdot C_{e}\right)$ was found to be fairly suited with the
ACT data. Both models predicted well the maximum uptake of activated charcoals as 68 and $351 \mathrm{mg} / \mathrm{g}$ for ACT and CAC, respectively with coefficient of determination, $R^{2}$ of 0.99 . In addition, a decreasing trend upon reaching the maximum methylene blue adsorption as demonstrated by ACT could be due to limited pore volume and drastic increase in solution density as a result of increasing methylene blue concentration. In other words, there is a possibility for the readily adsorbed toxin to be stripped from the activated charcoal due to rising concentration gradient. This could shed some light on the limitation of using 'under activated' charcoal for treating the poisonings. From Figure 2, the maximum uptake by ACT was achieved at initial methylene blue concentration of $126 \mathrm{mg} / \mathrm{L}\left(C_{e}=0.37 \mathrm{mg} / \mathrm{L}\right)$, exceeding which the adsorption starts to decline.

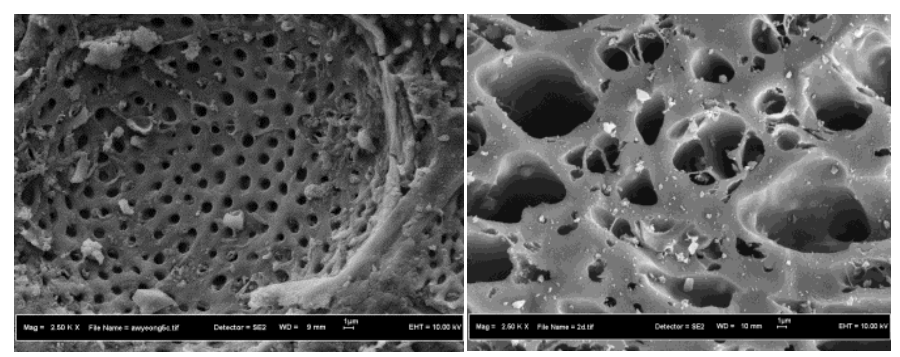

Fig. 1: Pore development after carbonization (left) and physical activation (right).
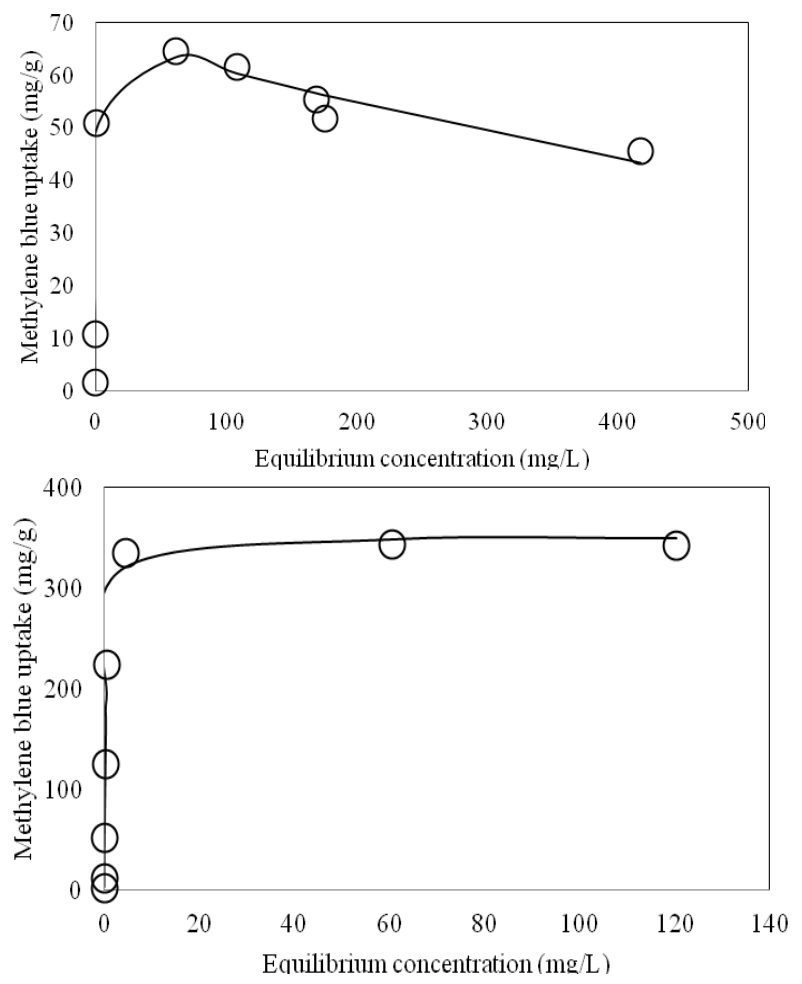

Fig. 2: Methylene blue uptake by activated charcoals (top: ACT; bottom: CAC; lines were predicted from models).

In conclusion, activated charcoal that we examined (DynaPharm) is not as 'activated' as it is claimed to be. 
Furthermore, the term 'activated' should not be used in the first place as it may give wrong impression and perception on its textural properties. The word 'activated' can only be used for carbon rich material with sufficient development of pores. Therefore, it is imperative for the resultant activated charcoal products to undergo characterization as early mentioned. On one hand, we would recommend only 'fully activated' charcoal for oral administration so as to avoid unnecessary overdose due to the substandard performance of activated charcoal in medicinal applications.

\section{ACKNOWLEDGEMENT}

This work was supported in part by University-Industry Research Laboratory (UTM Johor Bahru, \#Q.J091600.3100.00A37). M.A. Ahmad Zaini (PhD, CEng) gratefully acknowledges the Ministry of Higher Education Malaysia through the Fundamental Research Grant Scheme (FRGS, \#4F305). Authors also thank Prof. Tarik Omer Ogurtani (Middle East Technical University, Turkey) and Dr. Matthew J. Lennox (University of Nottingham, UK) for their fruitful discussion.

\section{REFERENCES}

Hall RG Jr, Thompson H, Strother A. Effects of orally administered activated charcoal on intestinal gas. Am. J. Gastroenterol., 1981; 75:192-196. Elsevier, 2006.

Marsh H, Rodriguez-Reinoso F. Activated Carbon. Amsterdam,

Ming-Twang S, Lin-Zhi L, Zaini MAA, Zhi-Yong Q, Pei-Yee AY. Activated carbon for dyes adsorption in aqueous solution. In: Advances in Environmental Research volume 36. Daniels JA (ed). USA, Nova Science Publishers, 2015, pp 217-234.

Neuvonen PJ, Kuusisto P, Vapaatalo H, Manninen V. Activated charcoal in the treatment of hypercholesterolaemia: dose-response relationships and comparison with cholestyramine. Eur. J. Clin. Pharmacol., 1989; 37: 225-230.

Olson KR. Activated charcoal for acute poisoning: one toxicologist's journey. J. Med. Toxicol., 2010; 6: 190-198.

Zaini MAA, Zakaria M, Mohd-Setapar SH, Che-Yunus MA. Sludge adsorbents from palm oil mill effluent for methylene blue removal. J. Environ. Chem. Eng., 2013; 1: 1091-1098.

\section{How to cite this article:}

Muhammad Abbas AHMAD ZAINI, Nur Atika MOHAMAD. Activated charcoal for oral medicinal purposes: Is it really activated? J App Pharm Sci, 2015; 5 (10): 157-159. 